\title{
Critical Role of the Prefrontal Cortex in the Regulation of Hippocampus-Accumbens Information Flow
}

\author{
Pauline Belujon and Anthony A. Grace \\ Departments of Neuroscience, Psychiatry, and Psychology, University of Pittsburgh, Pittsburgh, Pennsylvania 15260
}

The nucleus accumbens (NAc) is an integral part of limbic circuits proposed to play a central role in the pathophysiology of schizophrenia, and is positioned to integrate information from limbic and cortical regions, including the medial prefrontal cortex (mPFC) and the hippocampus. The ventral subiculum (vSub) of the hippocampus, in particular, is proposed to gate information flow within the NAc, a factor that is disrupted in models of schizophrenia. Using in vivo extracellular recordings in anesthetized rats, we examined the response of NAc neurons to vSub stimulation and how this is modulated by the mPFC. We found that inactivation of mPFC by tetrodotoxin attenuates the ability of the vSub to drive spike firing in the NAc. Thus, a contribution of the mPFC is required for the activation of NAc by the vSub. However, when long-term potentiation is induced in the vSub-NAc pathway, the vSub is now capable of driving the NAc without the participation of the mPFC. Moreover, this interaction is dependent on activation of dopaminergic $\mathrm{D}_{2}$ receptors in the NAc.

This work demonstrates the critical role of the MPFC in the ability of vSub to drive NAc neurons in normal anesthetized animals. One model of schizophrenia posits that vSub hyperactivity may underlie both the hyperdopaminergic state and disruption of information flow in this circuit in schizophrenia. Therefore, inactivation of the MPFC, as would occur with mPFC leukotomy in schizophrenia, may prevent the abnormal vSub drive of the NAc.

Key words: nucleus accumbens; hippocampus; prefrontal cortex; dopamine; schizophrenia; plasticity

\section{Introduction}

Anatomical (French and Totterdell, 2002, 2003) and electrophysiological (O'Donnell and Grace, 1995) studies show that the NAc receives convergent glutamatergic inputs from limbic and cortical structures such as the ventral subiculum of the hippocampus (vSub) and the medial prefrontal cortex (mPFC) that overlap with dopaminergic inputs from the ventral tegmental area (VTA) (Mogenson and Yang, 1991). Inputs to the NAc play unique roles in cognitive function, such as working memory, involving the mPFC (for review, see Goldman-Rakic, 1990) and contextdependent processing, implicating the vSub (Jarrard, 1995; Maren and Quirk, 2004). These inputs to the NAc are in addition regulated by different dopaminergic (DA) receptor subtypes. Thus, learning strategies are dependent on the interaction between the vSub inputs and NAc neurons. Moreover, this interaction is modulated by stimulation of $\mathrm{D}_{1}$ receptors by phasic DA release (Goto and Grace, 2005a), driven by DA neuron burst firing (Floresco et al., 2003). Furthermore, PFC-afferent input is dependent on $\mathrm{D}_{2}$ receptor stimulation by tonic $\mathrm{DA}$ release within the NAc, which suppresses PFC-dependent set shifting behaviors (Goto and Grace, 2005a). This suggests that there is a balance of information flow between mPFC control of behavioral flexibility

\footnotetext{
Received May 15, 2008; revised Aug. 19, 2008; accepted Aug. 21, 2008.

This work was supported by United States Public Health Service Grants DA15408 and MH57440 (A.A.G.) and an award from Fondation pour la Recherche Medicale (P.B.). We thank Niki MacMurdo and Emily Mahar for their technical assistance; Brian Lowry for the production, development, and support with the custom-designed electrophysiology software (Neuroscope); and Daniel Lodge for critical reading and helpful discussions.

Correspondence should be addressed to Pauline Belujon at the above address. E-mail: belujon@pitt.edu.

DOI:10.1523/JNEUROSCI.2200-08.2008

Copyright $\odot 2008$ Society for Neuroscience $\quad$ 0270-6474/08/289797-09\$15.00/0
}

and vSub control of context-related behavioral modulation that is differentially modulated by the DA system (for review, see Grace et al., 2007).

Postmortem (Falkai and Bogerts, 1986; Sherman et al., 1991) and imaging studies (Liddle et al., 1992; Raine et al., 1992; Tamminga et al., 1992; Bogerts et al., 1993) provide evidence that both structures play a role in schizophrenia. Thus, functional disruptions in these systems induce deficits consistent with those observed in schizophrenia such as interference with prepulse inhibition (Braff et al., 1992), thought to involve gating within the vSub (Caine et al., 2001), and working memory deficits (Weinberger and Gallhofer, 1997) involving the mPFC (Roberts et al., 1998). Early studies in schizophrenia patients suggest that mPFC disconnection may ameliorate psychosis observed in this disorder (Moniz, 1994), and mPFC lesions reverse dopaminergic deficits in animal models (Goto and O'Donnell, 2004). We propose that the dysfunction of information processing in schizophrenia arises in part from a disruption of homeostatic regulation by the mPFC and the DA system, leading to pathophysiology within hippocampal-NAc circuits.

Previous studies suggest that the mPFC provides a potent modulatory influence over subcortical systems, and furthermore, plasticity within $\mathrm{mPFC}$ afferents to the NAc can modulate vSub long-term potentiation (LTP) (Goto and Grace, 2005b). Moreover, the vSub provides an essential gating influence over the NAc (O'Donnell and Grace, 1995) and regulates the magnitude of phasic DA neuron activation (Lodge and Grace, 2007). In contrast, in this study we found that the mPFC also provides an essential permissive function that enables vSub-NAc drive to take place. Therefore, the mPFC appears to provide a differential 
influence on vSub-NAc drive that is dependent on the level of cortical activation. Moreover, this influence appears to be overridden when the vSub-NAc association is sufficiently well instantiated to lead to LTP within this circuit.

\section{Materials and Methods}

Animals. Adult male Sprague Dawley rats (Hilltop), weighing 300-400 g were used. Animals arrived at least 1 week before use and were housed two per cage under a $12 \mathrm{~h}$ light/dark cycle (light on at 7:00 A.M.) with temperature $\left(22^{\circ} \mathrm{C}\right)$ and humidity $(47 \%)$ regulation; food and water were available ad libitum. All animal experiments were performed in accordance with the guidelines outlined in the National Institutes of Health Guide for the Care and Use of Laboratory Animals and were approved by the Institutional Animal Care and Use Committee of the University of Pittsburgh.

Rats were anesthetized with chloral hydrate (400 mg/kg, i.p.), and anesthesia was maintained by supplemental intraperitoneal injection, as required to maintain suppression of the hindlimb withdrawal reflex. Rats were implanted with a catheter in the femoral vein to allow intravenous injections and mounted on a stereotaxic frame (Kopf). Body temperature was maintained at $37^{\circ} \mathrm{C}$ using a temperature-controlled heating pad (Fintronics).

Drugs and drug infusion. TTX, sulpiride, and Dulbecco's PBS (dPBS) were all obtained from Sigma-Aldrich. Sulpiride ( $5 \mathrm{mg} / \mathrm{kg}$ ) was dissolved in saline containing a drop of $\mathrm{HCl}$ for intravenous injections, and in dPBS for local injections $(3 \mu \mathrm{g}$ in $0.5 \mu \mathrm{l})$. TTX $(1 \mu \mathrm{M})$ was dissolved in dPBS. TTX $(1 \mu \mathrm{M}$ in $0.5 \mu \mathrm{l})$ and sulpiride $(3 \mu \mathrm{g}$ in $0.5 \mu \mathrm{l})$ were infused locally into the $\mathrm{mPFC}$ and the NAc, respectively, via a 33 gauge cannula at a rate of $0.5 \mu \mathrm{l}$ over $1 \mathrm{~min}$. dPBS $(0.5 \mu \mathrm{l})$ was infused locally into the $\mathrm{mPFC}$ and NAc for control experiments.

Electrophysiology. Single glass microfiber micropipette electrodes (WPI; impedance, $12-16 \mathrm{M} \Omega$ ) were filled with $2 \%$ Pontamine sky blue dye in $2 \mathrm{M} \mathrm{NaCl}$, and placed into the right NAc according to a rat brain atlas (Paxinos and Watson, 1996) [anteroposterior (AP), $1.5 \mathrm{~mm}$ anterior to bregma; lateral (L), $1.0 \mathrm{~mm}$ from the midline; dorsal (D), 5-7 mm from the dura] using a hydraulic microdrive (Narishige). Single-unit activity was amplified and filtered $(500-5000 \mathrm{~Hz})$ using an amplifier (Cygnus Technology). Recordings were displayed on an oscilloscope (Hitachi) and transferred via an interface to a computer equipped with custom-designed computer software (Neuroscope). Only neuronal activity with a signal-to-noise ratio $>3: 1$ was recorded and used for analyses.

Single-pulse and tetanic stimulation was applied via a concentric bipolar stimulating electrode (NEX-100X; Rhodes Medical Instruments) to the fimbria (AP, -1.3 posterior to bregma; $\mathrm{L}, 1.6 \mathrm{~mm}$ from the midline; $\mathrm{D}, 4 \mathrm{~mm}$ from the dura). A chemotrode or a cannula was placed into the $\mathrm{mPFC}$ [ $15^{\circ}$ angle; AP, $2.9 \mathrm{~mm}$ anterior to the bregma; $\mathrm{L}, 1.9$ from the midline; D, $3.0 \mathrm{~mm}$ from the dura (Laviolette and Grace, 2006)] allowing infusion of TTX at the stimulation site or into the orofacial area of the motor cortex ( $15^{\circ}$ angle; AP, $3.2 \mathrm{~mm}$ anterior to the bregma; $\mathrm{L}, 4.0$ from the midline; D, $1.0 \mathrm{~mm}$ from the dura), respectively.

Stimulation protocol. In the cell searching procedure, alternating stimuli (duration, $0.25 \mathrm{~ms}$; intensity, $1 \mathrm{~mA}$ ) were delivered to the fimbria and the mPFC (prelimbic cortex) (100 ms intervals every $2 \mathrm{~s}$ ), while the microelectrode was lowered through the NAc. Single current pulses were delivered using a dual output stimulator (S8800; Grass Technologies). Neurons that respond to stimulation of both areas were recorded and used for additional investigations (see Fig. 1A). Cells that did not respond monosynaptically to the fimbria stimulation [latency, 6-11 ms
B
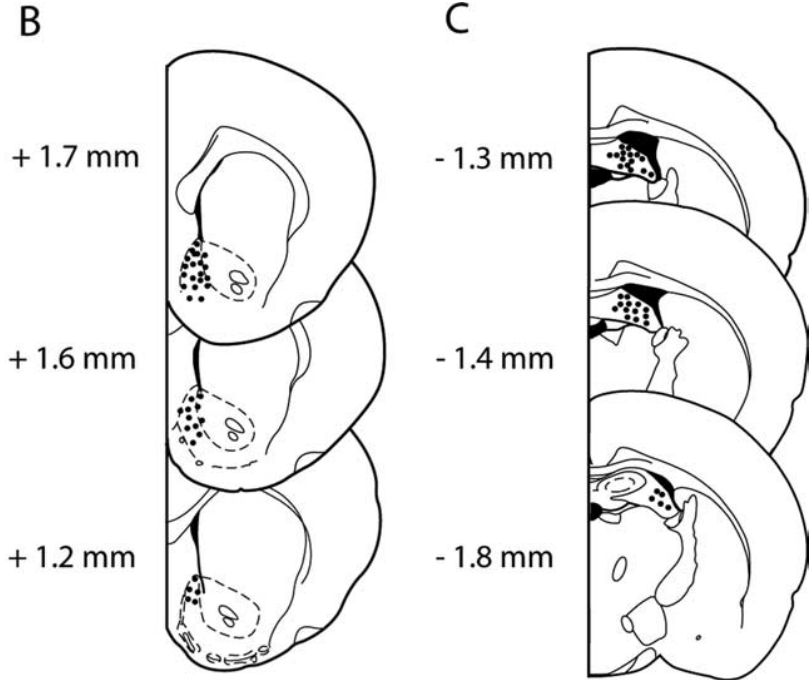
analysis.

After identifying a responsive neuron, only fimbria stimulation was delivered $(0.5 \mathrm{~Hz})$ and current intensity was adjusted to obtain $\sim 50 \%$ spike probability (intensity range, $0.2-1.3 \mathrm{~mA}$ ). Evoked spike probabilities were calculated by dividing the number of action potentials observed by the number of stimuli administered. Changes in spike probabilities were considered as changes in the influence that hippocampal inputs exert over NAc neurons (Floresco et al., 2001). Basal fimbria-evoked activity of NAc neurons was recorded for 5-10 min before TTX infusion or tetanic stimulation to ascertain the stability of the activity. After 10 min, TTX ( $1 \mu \mathrm{M}$ in $0.5 \mu \mathrm{l})$ was infused into the mPFC and evoked activity was recorded for at least $20 \mathrm{~min}$ after the infusion. In a subset of experiments, after $10 \mathrm{~min}$ of baseline recordings tetanic stimulation was applied [ $20 \mathrm{~Hz}, 200$ pulses, suprathreshold intensity (Floresco et al., 2001)] to the fimbria, and subsequent evoked activity was recorded for at least 30 min after the tetanus. In another set of experiments, TTX was administered into the mPFC 20 min after tetanic stimulation of the fimbria and activity was recorded for at least $30 \mathrm{~min}$. After tetanus, $0.5 \mathrm{~Hz}$ fimbria stimulation was applied at the same current intensity as that used to assess basal evoked activity. Finally, in another set of experiments, tetanic stimulation of the fimbria was recorded $10 \mathrm{~min}$ after TTX infusion into the mPFC.

In experiments in which sulpiride was injected ( $5 \mathrm{mg} / \mathrm{kg}$, i.v.), subsequent evoked activity was recorded for $5 \mathrm{~min}$ before either application of tetanic stimulation of the fimbria or infusion of TTX/dPBS into the mPFC. Local infusions of sulpiride ( $3 \mu \mathrm{g}$ in $0.5 \mu \mathrm{l}$ ) (or dPBS as a control) into the NAc (AP, $1.5 \mathrm{~mm}$ from the bregma; $\mathrm{L}, 1.0 \mathrm{~mm}$ from the midline; $\mathrm{D}, 6.0 \mathrm{~mm}$ from the dura) were done before initiation of the cell searching procedure to ensure stability of the preparation.

All data were normalized to the average spike probability obtained in baseline conditions, and are shown and analyzed as percentage change in spike probabilities.

Histology. At the end of each experiment, the recording site was marked via electrophoretic ejection of Pontamine sky blue dye from the tip of the recording electrode ( $-25 \mu \mathrm{A}$ constant current; $20-30 \mathrm{~min}$ ). Rats were killed by an overdose of chloral hydrate (additional $400 \mathrm{mg} / \mathrm{kg}$, i.p.) and decapitated. The brain was removed, fixed for at least $48 \mathrm{~h} \mathrm{(8 \%}$ w/v paraformaldehyde in PBS), and cryoprotected (25\% w/v sucrose in PBS) until saturated. Brains were sectioned ( $60 \mu \mathrm{m}$ coronal sections), mounted onto gelatin-chromalum-coated slides, and stained with cresyl violet for histochemical verification of recording electrode and/or cannula placement sites. Localization of the stimulation electrode in the 

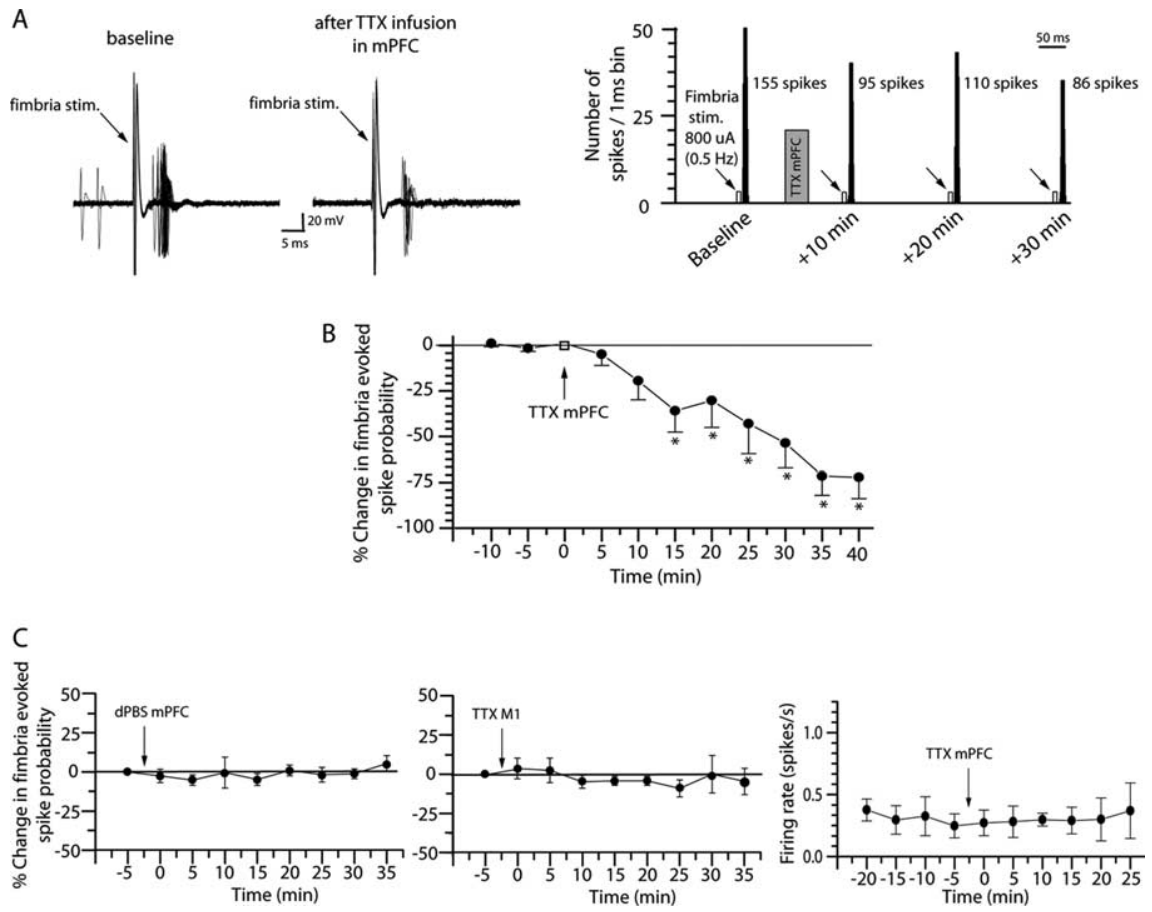

Figure 2. Inactivation of the mPFC decreases vSub drive of NAC. $\boldsymbol{A}$, Extracellular recording traces (top) and peristimulus time histograms (bottom; 10 min samples; 300 sweeps) showing a representative example of the inhibitory effect of TTX infusion (1 $\mu \mathrm{m} / 0.5 \mu \mathrm{l}$ ) into the mPFC on the fimbria-evoked spike probability recorded from a NAc neuron, 10, 20, and 30 min after TTX infusion. The arrows indicate the time at which fimbria is stimulated. $\boldsymbol{B}$, Mean percentage change ( \pm SEM) of the fimbria-evoked spike probability normalized to the baseline spike probability before tetanus. TTX infusion into the MPFC significantly decreases the fimbria-evoked spike probability of NAc neurons; the attenuation lasts longer than 30 min. ${ }^{*} p<0.05$. C, Infusion of dPBS in $\mathrm{mPFC}$ had no effect on the fimbria-evoked spike probability of NAc neurons (left panel; $n=8$ ). Infusion of TTX in the motor cortex has no significant effect on the fimbria-evoked spike probability of NAc neurons (middle panel; $n=5$ ), and TTX in the mPFC has no significant effect on the firing rate of NAc neurons (right panel; $n=5$ ).

fimbria, the chemotrode in the mPFC, and the recording electrode in the NAc are shown in Figure 1.

Data analysis. Data were analyzed using a one-way ANOVA with repeated measures followed by the Holm-Sidak test, with time as the within-subject factor. Multiple comparisons were analyzed using a twoway ANOVA followed by the Holm-Sidak test, with treatment as the between-subject factor and time as the within-subject factor.

\section{Results}

Stimulation electrodes were placed in the prelimbic segment of the $\mathrm{mPFC}$ (Fig. $1 \mathrm{~A}$ ) and in the fimbria (Fig. $1 C$ ), and recordings were made primarily in the shell region of the NAc and, in some cases, the medial part of the core of the NAc (Fig. $1 B$ ). NAc neurons have been shown to receive converging inputs from the vSub of the hippocampus and the mPFC (O'Donnell and Grace, 1995; French and Totterdell, 2002). Single pulse stimulation of these afferent regions evoked action potential discharge in NAc neurons. For all neurons used in this study, the latency of the monosynaptic response of NAc neurons after fimbria stimulation was $8.0 \pm 0.2 \mathrm{~ms}(n=99)$, which is consistent with previous reports (O’Donnell and Grace, 1995; Mulder et al., 1998). The mean baseline spike probability was $0.45 \pm 0.01$, and the baseline current intensity to obtain $\sim 50 \%$ spike probability was $622 \pm 32$ $\mu \mathrm{A}(n=99)$.

\section{The mPFC is necessary for the activation of NAc neurons by the vSub}

To establish whether inactivation of the mPFC affected vSub stimulation-induced spike firing in the NAc, TTX $(1 \mu \mathrm{M})$ was infused into the mPFC 5 min after recording stable baseline activity and evoked response probability ( $\leq 10 \%$ change). In all neurons tested (14 of $14 ; 100 \%)$, infusion of TTX $(1 \mu \mathrm{M})$ into the mPFC resulted in a significant decrease of the fimbria-evoked spike probability in the NAc $(F=8.592$; $p<0.05$ ) (Fig. 2). The decrease reached significant levels at $15 \mathrm{~min}$ after TTX infusion and remained depressed for at least 30 min. Thus, the spike probability decreased from $0.48 \pm 0.02$ (baseline) to $0.12 \pm 0.04$ $35 \mathrm{~min}$ after the infusion, corresponding to a $72 \pm 10 \%$ decrease (Fig. 2 B). A return to the baseline spike probability did not occur within the period of recording (i.e., up to 55 min after infusion).

Infusion of dPBS $(0.5 \mu \mathrm{l})$ into mPFC did not affect the fimbria-evoked spike probability (NS; $n=8$ ) (Fig. $2 C$, left). Infusion of TTX was performed in the motor cortex to examine the specificity of the effect of TTX infusion in the mPFC on the vSub-NAc evoked response. No significant change was observed before and after TTX infusion in the motor cortex (NS; $n=5$ ) (Fig. $2 C$, middle). To examine whether the effect of TTX in the MPFC was specific for the vSub-NAc pathway or may have been attributable to a nonspecific decrease in NAc neuron excitability, the effect of the inactivation of mPFC on spontaneous activity of NAc neurons was tested. No significant alteration in baseline spike firing rate occurred within the 20 min recording period (baseline firing, $0.31 \pm 0.1 \mathrm{spikes} / \mathrm{s}$; firing rate $20 \mathrm{~min}$ after TTX, $0.29 \pm 0.1$ spikes $/ \mathrm{s} ; F=1.962$; NS; $n=5$ ) (Fig. $2 C$, right).

\section{vSub-NAc LTP attenuates the effects of mPFC inactivation}

Tetanic stimulation delivered to the fimbria induced a persistent facilitation of the vSub-NAc pathway (LTP) (Fig. $3 A, B$ ), which was similar to that described after a similar stimulation protocol (Floresco et al., 2001; Goto and Grace, 2006). Thus, 10 min after tetanic stimulation, there was a significant increase in fimbriaevoked spike probability $(52 \pm 15 \% ; F=4.714 ; p<0.05 ; n=10)$ (Fig. $3 B$ ) that lasted for $>30 \mathrm{~min}$.

The effects of mPFC inactivation after vSub-NAc LTP was examined by infusing TTX into the MPFC $20 \mathrm{~min}$ after tetanic stimulation of the fimbria. After induction of LTP in this pathway, inactivation of the $\mathrm{MPFC}$ no longer affected fimbria-evoked spike probability in the NAc (Fig. $3 C, D$ ). Thus, tetanic stimulation induced a significant increase in the spike probability that was now resistant to the attenuation observed after infusion of the TTX into the $\operatorname{mPFC}(F=7.468 ; p<0.05 ; n=16)$ (Fig. $3 D)$. Moreover, the evoked spike probability after $\mathrm{mPFC}$ inactivation was within a 95\% confidence interval of the posttetanus level (posttetanus/pre-mPFC inactivation, $0.62 \pm 0.03$; after tetanus and mPFC inactivation, $0.60 \pm 0.04$; confidence interval, $0.56-$ 0.68 ). In both cases, a significant transient decrease of the spike probability was observed immediately after tetanic stimulation (this is not readily observed in Fig. 3 because of 5 min epoch averaging) (Fig. 4). 
A

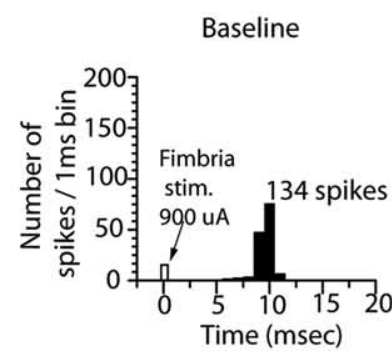

C

Baseline

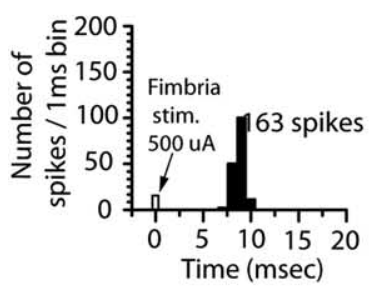

E

Baseline

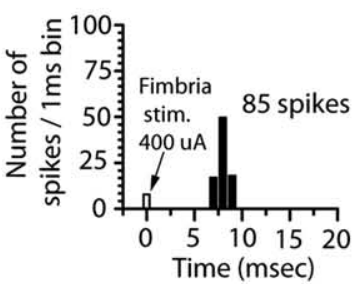

20 minutes after tetanus
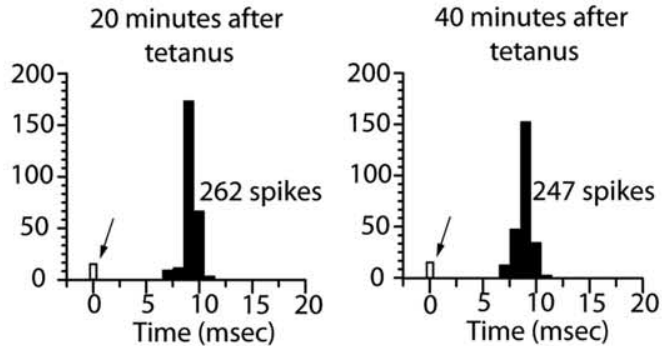

B

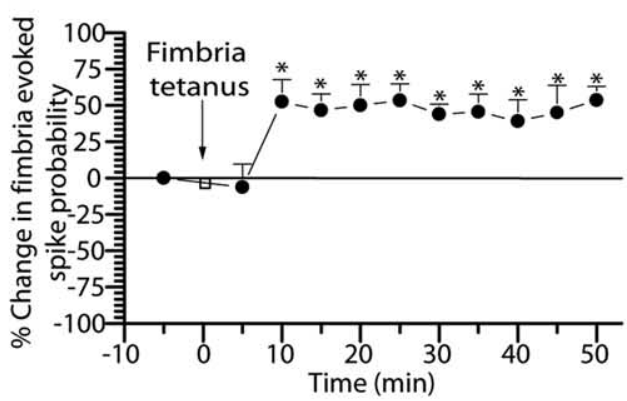

20 minutes after tetanus
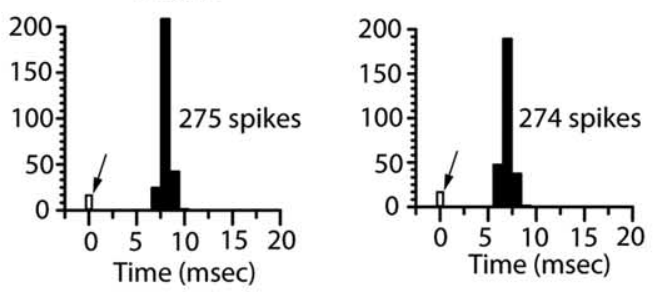

20 minutes after MPFC TTX infusion

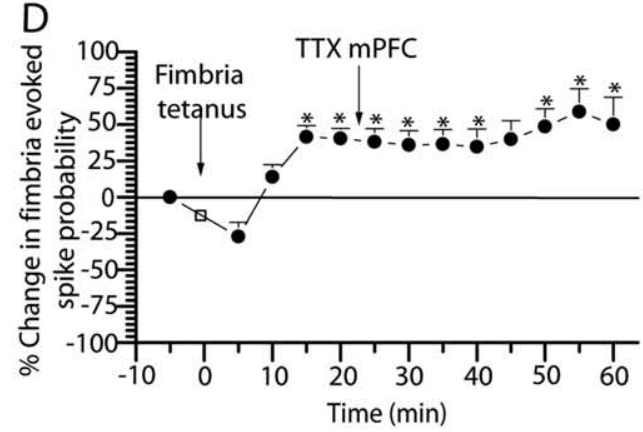

$\mathrm{F}$

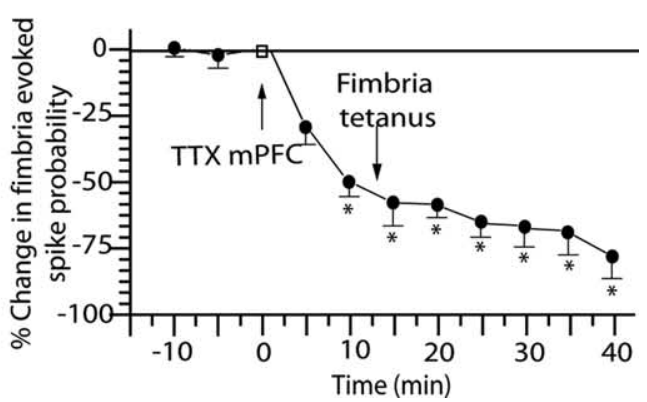

Figure 3. Potentiation of fimbria-evoked spike discharge of NAc neurons circumvents the effects of $\mathrm{mPFC}$ inactivation on the vSub-NAc pathway. $A$, Representative peristimulus time histogram (10 min samples; 300 sweeps) of the induction of LTP into the vSub-NAc pathway 20 and 40 min after tetanic stimulation ( $20 \mathrm{~Hz} ; 200$ pulses; $+0.1-0.2 \mathrm{~mA}$ to the threshold intensity) of hippocampal afferents. The arrows indicate the time at which the fimbria is stimulated. $\boldsymbol{B}$, Fimbria-evoked activity is potentiated by tetanic stimulation of the fimbria, and this potentiation lasts longer than $45 \mathrm{~min}(n=10)$. C, Peristimulus time histogram (10 min samples) of representative fimbria-evoked activity recorded from a NAc neuron 20 min after tetanic stimulation and 20 min after TTX infusion into the $\mathrm{mPFC}$. The arrows indicate the time at which the fimbria is stimulated. D, LTP is induced $15 \mathrm{~min}$ after the fimbria tetanic stimulation and lasts for 30 min. Enhancement of the evoked activity is not changed by infusion of TTX into the MPFC (NS; $n=16$ ). $\boldsymbol{E}$, Representative peristimulus time histogram ( 5 min samples; 150 sweeps) showing inhibitory effect 10 min after TTX infusion $(1 \mu \mathrm{m} / 0.5 \mu \mathrm{l})$ into the $\mathrm{mPFC}$ on the fimbria-evoked spike probability recorded from a NAc neuron, and 10 min after tetanic stimulation of the fimbria $(\boldsymbol{F})$. Tetanic stimulation is only effective in obviating the need for the mPFC if it is delivered before mPFC inactivation, because tetanic stimulation ( $20 \mathrm{~Hz} ; 10 \mathrm{~s}$; suprathreshold intensity) of the fimbria does not reverse the significant decrease induced by infusion of TTX in the mPFC $(n=6)$. Error bars indicate SEM. ${ }^{*} p<0.05$.

The tetanic stimulation must be given before mPFC inactivation for it to effectively diminish the requirement of an intact $\mathrm{mPFC}$. This was shown by administering tetanus $(20 \mathrm{~Hz} ; 10 \mathrm{~s})$ to the fimbria $10 \mathrm{~min}$ after infusion of TTX in the mPFC (Fig. $3 E, F)$. In all neurons tested (six of six; $100 \%$ ), infusion of TTX induced a significant decrease in the spike probability $10 \mathrm{~min}$ after the infusion $(p<0.05 ; n=6)$ that is not reversed by tetanic stimulation of the vSub-NAc pathway (NS; $n=6)($ Fig. $3 F)$. Thus, the spike probability decreased from $0.50 \pm 0.03$ (baseline) to $0.26 \pm 0.05,10 \mathrm{~min}$ after TTX infusion, and to $0.22 \pm 0.0510$ min after tetanic stimulation of the fimbria. A return to the baseline spike probability did not occur within the period of recording (i.e., up to 60 min after infusion). These data demonstrate that, after induction of LTP in the vSub-NAc pathway, the mPFC is no longer required to support vSub-NAc drive.
Tetanic stimulation of the vSub-NAc pathway evokes $D_{2}-$ induced attenuation of vSub drive

Several studies have shown that tetanic stimulation applied to hippocampal afferents induces an increase in tonic dopamine levels in the NAc (Blaha et al., 1997; Floresco et al., 1998, 2001). This mesoaccumbens DA release was found to enhance hippocampal-evoked activity in NAc neurons via a $D_{1}$ dependent mechanism. However, in these experiments, we observed a short-term attenuation of vSub-driven spike activity in the NAc after tetanic stimulation-induced LTP. Thus, before development of the LTP in this pathway, a significant transient decrease $(52.3 \pm 8.0 \% ; p<0.05 ; n=36)$ of the fimbria-evoked spike probability was observed immediately after tetanic stimulation. Thus, the spike probability decreased from $0.43 \pm 0.033$ min before the tetanus to $0.15 \pm 0.031 \mathrm{~min}$ immediately after the 

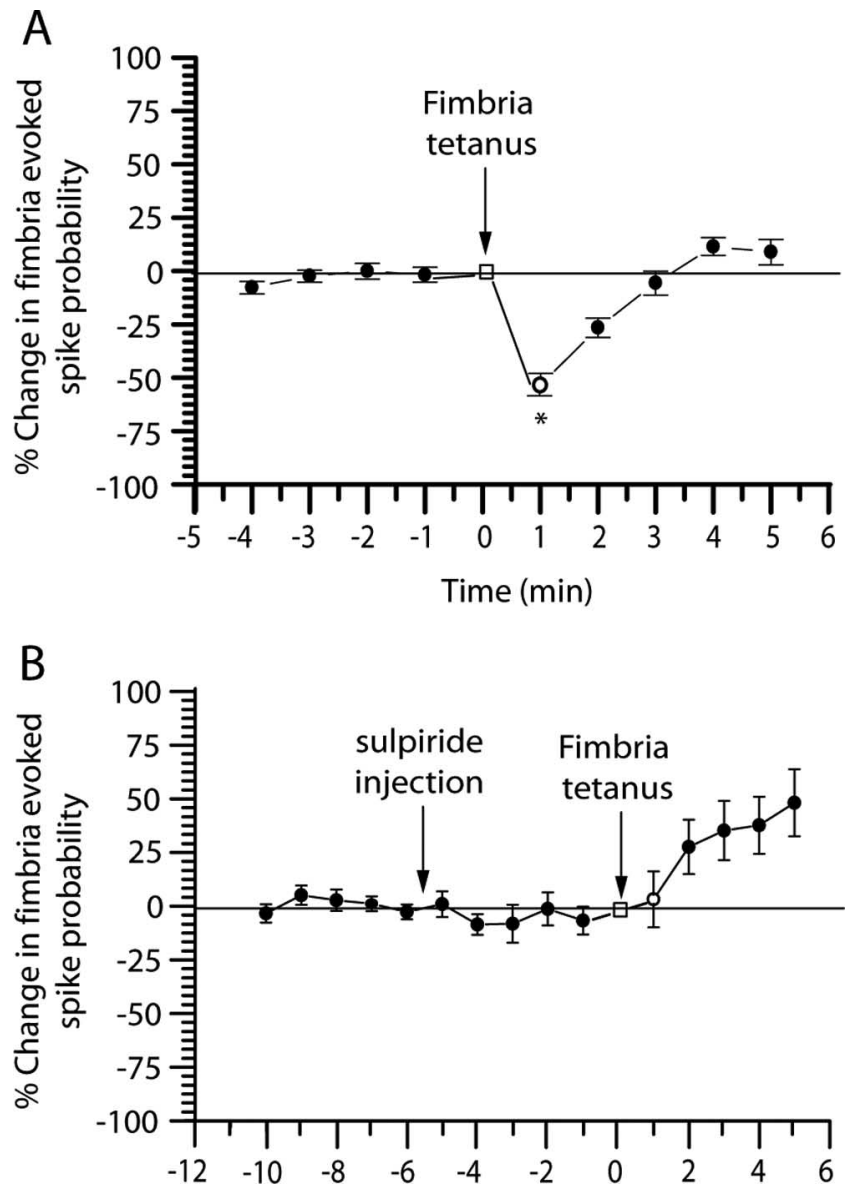

Figure 4. Sulpiride blocks the transient attenuation of vSub-NAc drive after tetanic stimulation. $\boldsymbol{A}$, When displayed on a expanded time base, a significant transient decrease in fimbriaevoked spike probability is revealed immediately after tetanic stimulation and has a duration of $\sim 1$ min (open circle) ( $n=36$ ). The arrow indicates the time at which tetanic stimulation and TTX infusion are applied to the fimbria and the $\mathrm{MPFC}$, respectively. $\boldsymbol{B}$, The transient decrease observed after the tetanic stimulation is blocked by previous systemic administration of sulpiride ( $5 \mathrm{mg} / \mathrm{kg}$; open circle) $(n=17)$. The arrow indicates at which time tetanic stimulation is applied to the fimbria. Error bars indicate SEM. ${ }^{*} p<0.05$.

tetanic stimulation $(F=3.788 ; p<0.05 ; n=36)$ (Fig. $4 A)$. This effect persisted for $\sim 1 \mathrm{~min}$.

We propose that this may be attributable to a $\mathrm{D}_{2}$-mediated attenuation of mPFC facilitation of this pathway, because $\mathrm{D}_{2}$ receptors are known to inhibit $\mathrm{mPFC}$ drive of the NAc (O'Donnell and Grace, 1994). This was tested by examining the effect of the selective $\mathrm{D}_{2}$ antagonist sulpiride ( $5 \mathrm{mg} / \mathrm{kg}$, i.v.) on the tetanic stimulation-induced attenuation of vSub-NAc drive. In all neurons tested (16 of 16), the injection of sulpiride before the application of tetanus blocked the short-term attenuation of vSub-NAc drive (Fig. 4B). Thus, after sulpiride, there was a significant attenuation of tetanus-evoked inhibition of fimbriaevoked NAc activity compared with that observed without sulpiride preinjection (spike probability, $0.19 \pm 0.011 \mathrm{~min}$ after tetanic stimulation without preinjection of sulpiride vs $0.43 \pm$ 0.03 in rats in which sulpiride injection preceded tetanic stimulation; $n=36$ and 16 , respectively) $(F=2.760 ; p<0.05)$ (Fig. 4). It should be noted that in a few cases $(n=5$ of $41 ; 12 \%)$, tetanic stimulation of the fimbria induced a robust decrease of the spike probability of the vSub-NAc pathway that lasted for $30 \mathrm{~min}$ [long-term depression (LTD)] (data not shown). Similar LTD was never observed after injection of sulpiride.

\section{$D_{2}$ receptor blockade enables $m P F C$ inactivation to reverse} vSub-NAc LTP

After injection of sulpiride, tetanic stimulation induced LTP that was not significantly different with respect to amplitude and time course from that observed in the absence of the drug $(F=1.249$; NS; $n=7)$. Thus, $10 \mathrm{~min}$ after application of the tetanus, a significant increase (LTP, $+39.6 \pm 8.2 \%)$ in fimbria-evoked NAc drive is observed $(F=6.213 ; p<0.05)$ that lasted for at least 30 min (Fig. 5A). When sulpiride was injected 15 min after tetanus, no significant difference was observed in the potentiation of the spike probability before $(59.6 \pm 18.0 \%$ increase $)$ or after injection of sulpiride $(38.1 \pm 19.1 \%$ increase $)(F=2.576 ; n=5$; NS) (data not shown). Thus, $\mathrm{D}_{2}$ receptor blockade had no effect on the induction or on the maintenance of the LTP induced by tetanic stimulation of the fimbria.

Given evidence demonstrating the importance of dopamine in modulating NAc afferent drive (O’Donnell and Grace, 1994; Goto and Grace, 2005b), the effects of sulpiride after vSub tetanus was evaluated. In the presence of sulpiride, inactivation of the mPFC with TTX now potently attenuated vSub-NAc drive after fimbria tetanus (Fig. 5B). Thus, in all cases examined, after sulpiride, $\mathrm{mPFC}$ inactivation completely reversed the vSub-NAc LTP previously induced by the tetanus (spike probability before mPFC inactivation, $0.69 \pm 0.04$ vs $0.46 \pm 0.04$ after inactivation; $F=6.336 ; p<0.05 ; n=9)$. The resultant evoked spike probability was within a $95 \%$ confidence interval of the pretetanus baseline level (pretetanus baseline, $0.40 \pm 0.04$; after tetanus and mPFC inactivation, $0.46 \pm 0.04$; confidence interval, $0.31-0.49$ ).

If sulpiride is injected after LTP induction (15 min after tetanic stimulation of the fimbria), inactivation of the $\mathrm{MPFC}$ had no effect on the maintenance of the potentiation (Fig. 5E,F). Thus, 15 min after tetanus, a $78.5 \pm 18.7 \%$ potentiation was observed (spike probability, $0.69 \pm 0.06$, vs baseline probability, $0.41 \pm 0.01 ; F=2.352 ; n=5 ; p<0.05)$. Infusion of TTX had no significant effect on the potentiation that was observed before injection of sulpiride. Thus, the spike probability after infusion of TTX was within a 95\% confidence interval of the presulpiride potentiation level (posttetanus, presulpiride, $0.69 \pm 0.06$ : postsulpiride, post-TTX, $0.67 \pm 0.07$; confidence interval, $0.38-1.00)$. Thus, $\mathrm{D}_{2}$ receptor stimulation must be available during the tetanus to produce long-term LTP.

\section{The ability of sulpiride to enable mPFC inactivation-induced} reversal of LTP is attributable to a local effect in the NAC

As shown above, systemic administration of sulpiride before tetanic stimulation enabled $\mathrm{mPFC}$ inactivation to reverse fimbria stimulation-induced LTP. To examine the locus of this response, the effects of local sulpiride administration within the NAc on LTP was examined. In this set of experiments, sulpiride ( $3 \mu \mathrm{g}$ in $0.5 \mu \mathrm{l})$ was infused directly into the NAc shell before recording electrophysiological activity of NAc neurons. After $10 \mathrm{~min}$ of recording of baseline activity, tetanic stimulation was applied to the fimbria, resulting in a significant potentiation $(+115.9 \pm$ $30.9 \% ; 10$ min after tetanic stimulation; $n=6)$ of the vSub-NAc drive in all neurons tested (baseline, $0.38 \pm 0.03 ; 10$ min after tetanus, $0.76 \pm 0.05 ; F=7.902 ; p<0.05$; six of six). As with systemic administration, local sulpiride blocked the transient attenuation of vSub-NAc drive (Fig. 6A). Moreover, as with systemic sulpiride administration, subsequent infusion of TTX into the mPFC was found to reverse the vSub-NAc LTP (pre-TTX spike probability, $0.76 \pm 0.05$ at $10 \mathrm{~min}$ posttetanic stimulation, vs $0.38 \pm 0.02,10 \mathrm{~min}$ after TTX infusion; $n=6, F=20.17 ; p<$ 0.05 ) (Fig. $6 B$ ). The resultant evoked spike probability was within 
A
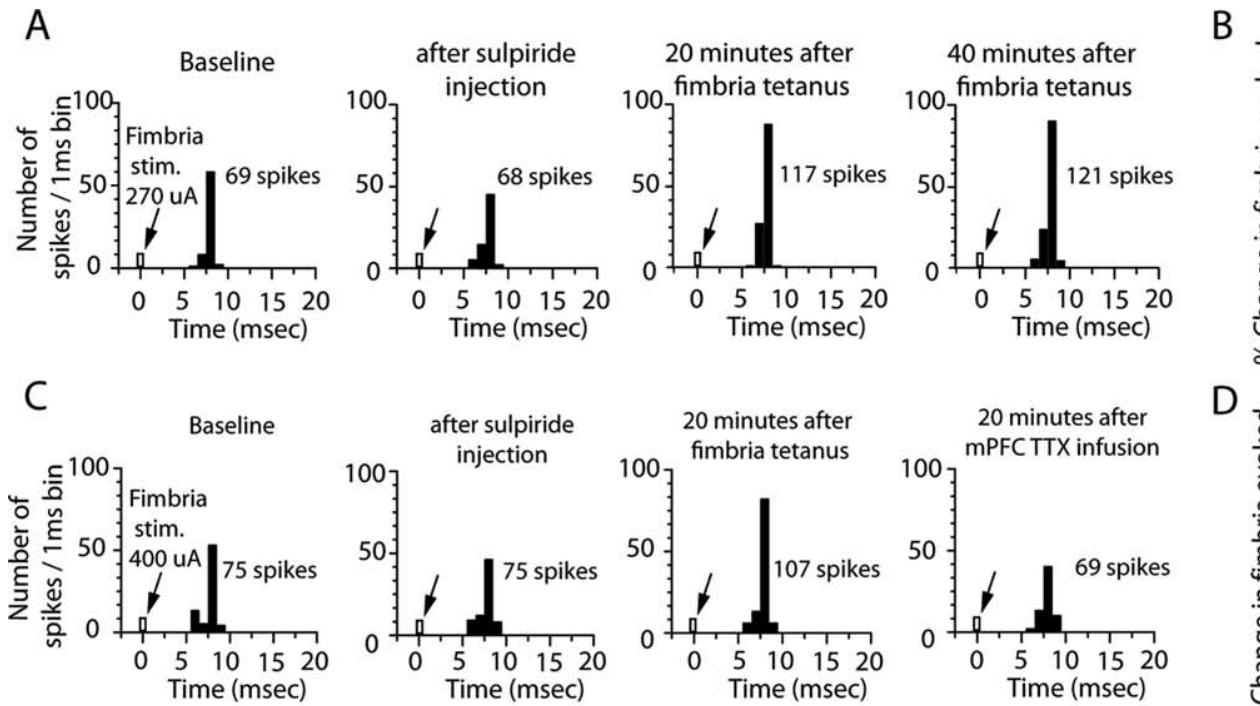

D
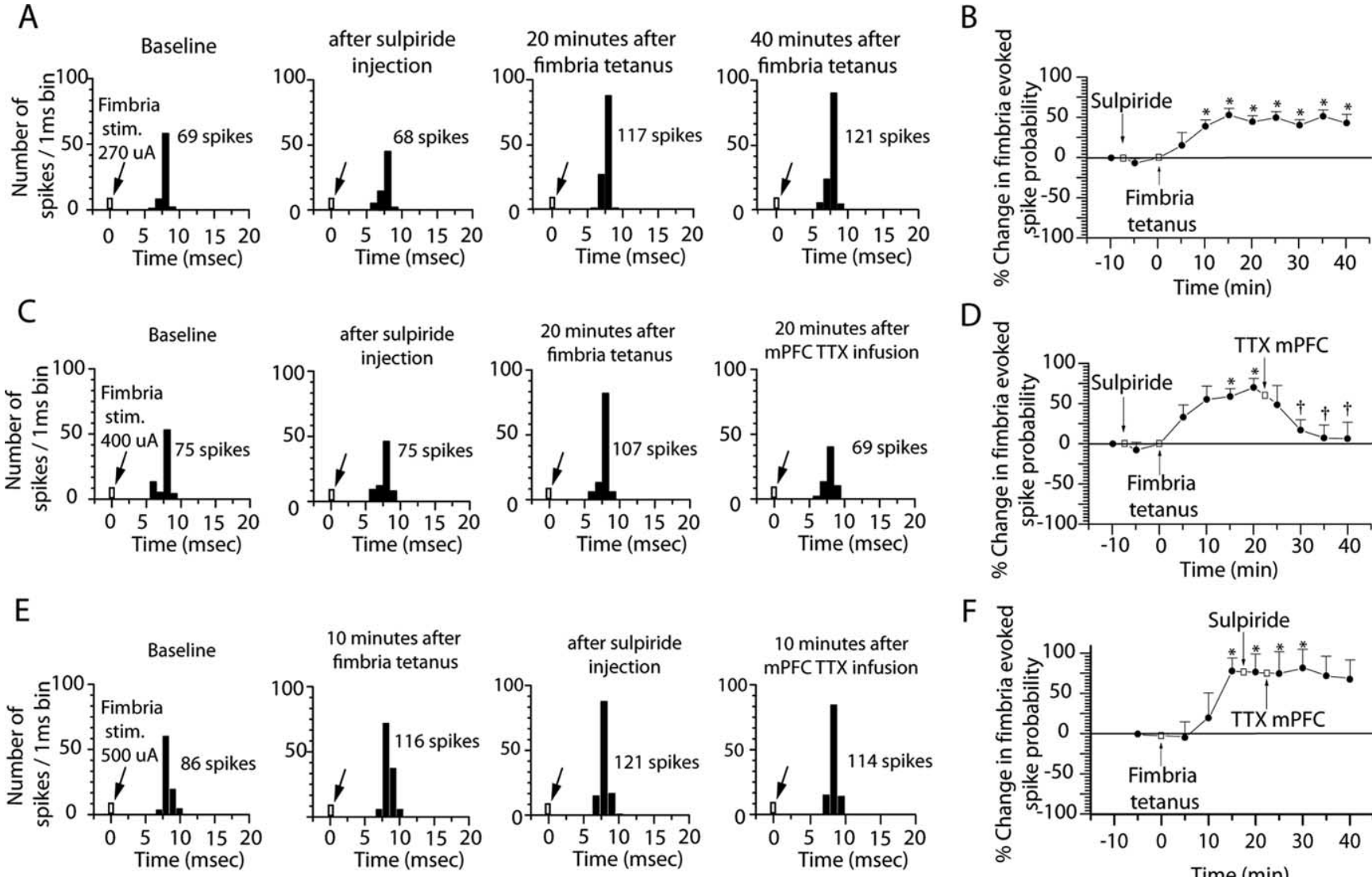

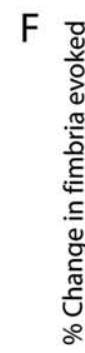

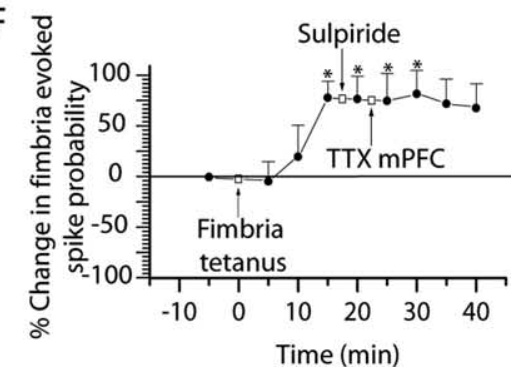

Figure 5. $D_{2}$ receptor blockade restores the effects of mPFC inactivation on the vSub-NAc pathway. $A$, Peristimulus time histogram ( 5 min samples; 150 sweeps) of a typical response to fimbria stimulation recorded from a NAc neuron $5 \mathrm{~min}$ after intravenous sulpiride $(5 \mathrm{mg} / \mathrm{kg})$ injection and 20 and $40 \mathrm{~min}$ after tetanic stimulation of hippocampal afferents. The arrows indicate the time at which the fimbria is stimulated. $\boldsymbol{B}$, LTP is induced $10 \mathrm{~min}$ after tetanic stimulation of the fimbria and lasts for $>35 \mathrm{~min}(n=7)$. C, Peristimulus time histogram ( 5 min samples) of a typical response to fimbria stimulation recorded from a NAc neuron 5 min after intravenous injection of sulpiride, 20 min after fimbria tetanus, and 20 min after TTX infusion into the mPFC. The arrows indicate the time at which the fimbria is stimulated $(n=9)$. $\boldsymbol{D}$, LTP is induced $10 \mathrm{~min}$ after fimbria tetanic stimulation. Ten minutes after infusion of TTX into the mPFC, there is a return to baseline spike probability. $\boldsymbol{E}$, Peristimulus time histogram (5 min samples) of a typical response to fimbria stimulation recorded from a NAc neuron, 10 min after fimbria tetanus, 5 min after intravenous injection of sulpiride, and $10 \mathrm{~min}$ after TTX infusion into the mPFC. The arrows indicate the time at which the fimbria is stimulated. $F$, LTP is induced 15 min after fimbria tetanic stimulation. When intravenous injection of sulpiride is performed after tetanus, no return to baseline spike probability is observed after infusion of $\operatorname{TTX}$ in the $\mathrm{mPFC}(n=5)$. Error bars indicate SEM. ${ }^{*} p<0.05$.

a 95\% confidence interval of the predrug baseline level (pretetanus baseline, $0.37 \pm 0.03$; after tetanus and $\mathrm{mPFC}$ inactivation, $0.34 \pm 0.02$; confidence interval, $0.37 \pm 0.08$ ) (Fig. $6 B$ ). Moreover, this was not attributable to a disruptive influence of the infusion procedure, because infusion of vehicle (distilled PBS, $0.5 \mu \mathrm{l}$ ) failed to enable $\mathrm{mPFC}$ inactivation to reverse fimbria tetanus-induced LTP (pre-TTX probability, $0.63 \pm 0.09$; after mPFC TTX, $0.68 \pm 0.01$; confidence interval, $0.63 \pm 0.39 ; n=3$ ) (data not shown).

\section{Discussion}

Our previous studies have shown that, with tetanic stimulation of mPFC and vSub, these regions compete for the control of NAc neurons (Goto and Grace, 2005b). In contrast, the present study shows that the initiation of vSub drive of the NAc requires a contributory role of the $\mathrm{mPFC}$. Thus, at the earliest stage of activation, the mPFC must exert a permissive action to allow the vSub to control the NAc, indicating a dependence on the mPFC of the vSub drive of NAc neurons (Fig. 7B). However, in the case in which the vSub-NAc drive is sufficient to result in the induction of LTP, the participation of the $\mathrm{MPFC}$ is no longer required to enable vSub-NAc drive (Fig. $7 C$ ). Moreover, the mPFC influence on the vSub-NAc pathway is $\mathrm{D}_{2}$ dependent (Fig. $7 D$ ).

\section{A novel role of the MPFC on the vSub-NAc circuit}

Inactivation of the MPFC with TTX was found to potently attenuate the ability of the vSub to drive spike firing in the NAc without affecting NAc neuron baseline firing. Moreover, inhibition of the vSub-NAc pathway seems sufficiently robust to not be reversed by tetanic stimulation of this pathway once the facilitative influence of the $\mathrm{mPFC}$ is removed. Previous studies reported a functional competition between these two structures. Thus, tetanic stimulation of the MPFC will induce a LTP in this pathway to the NAc and a LTD of the vSub-NAc pathway. Moreover, tetanic stimulation of the vSub will cause LTP in this pathway to the NAc and a LTD of the mPFC-NAc pathway (Goto and Grace, 2005b). Furthermore, Goto and O'Donnell showed that mPFC stimulation can attenuate NAc responses to vSub stimulation, and tetanic stimulation of the $\mathrm{mPFC}$ was found to reverse vSub-NAc LTP induced by cocaine sensitization (Goto and O'Donnell, 2002; Goto and Grace, 2005b). Our results demonstrate that interactions between these two structures are not only based on a direct competition but that activity within the mPFC is required to potentiate the vSub input to the NAc in normal conditions, highlighting a novel role of the $\mathrm{mPFC}$ in the modulation of this circuit. 

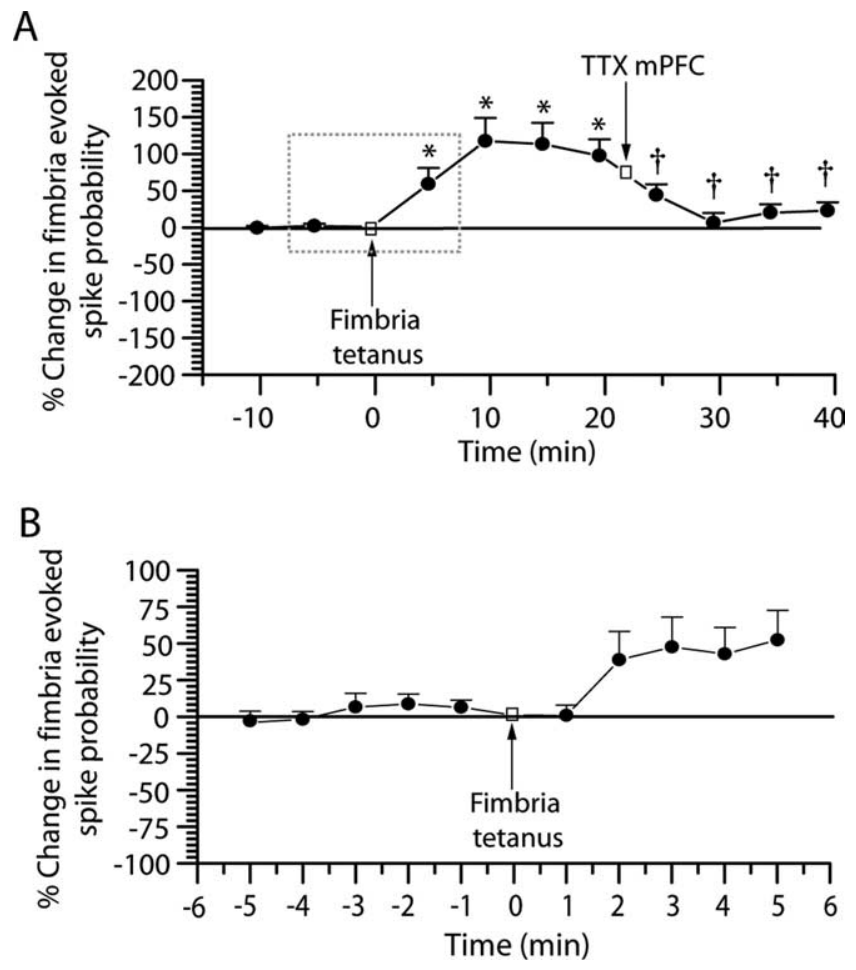

Figure 6. The effects of sulpiride are mediated within the NAc. $\boldsymbol{A}$, Local application of sulpiride blocks the short-term decrease in spike probability immediately after tetanus of the fimbria. The change in spike probability is sampled every minute for $10 \mathrm{~min}(5 \mathrm{~min}$ before and 5 min after tetanic stimulation). The arrow indicates the time at which tetanic stimulation and TTX infusion are applied to the fimbria and the MPFC, respectively. $\boldsymbol{B}$, Percentage change in spike probability (5 min samples) recorded after local infusion of sulpiride $(3 \mu \mathrm{g} / 0.5 \mu \mathrm{l}$ ) into the shell region of the NAc. LTP is induced $10 \mathrm{~min}$ after tetanic stimulation of the fimbria. Ten minutes after infusion of TTX into the mPFC, there is a return to baseline spike probability ( $n=$ 6). Error bars indicate SEM. ${ }^{*} p<0.05$ compared with the baseline; ${ }^{\dagger} p<0.05$ compared with the LTP.

\section{The modulatory influence of the mPFC on the vSub-NAc pathway is history dependent}

Our study demonstrates that the nature of the mPFC-vSub interaction depends on previous activity within these pathways to the NAc. Indeed, when LTP is induced in the vSub-NAc pathway, inactivation of the mPFC no longer affects this vSub-NAc pathway. Therefore, when the direct vSub-NAc pathway is enhanced, the $\mathrm{mPFC}$ is no longer required. Previous studies have shown that, during hippocampus activation, increased tonic and phasic dopaminergic transmission activates $\mathrm{D}_{1}$ and $\mathrm{D}_{2}$ receptors (Goto and Grace, 2005a) to shift the balance of information flow in the NAc from PFC to vSub by facilitating LTP in vSub and LTD at mPFC inputs (Goto and Grace, 2005b). Thus, activation of $\mathrm{D}_{2}$ receptors localized on presynaptic fibers of $\mathrm{mPFC}$ by tonic $\mathrm{DA}$ levels will inhibit this pathway as well.

Tetanic stimulation of the fimbria evoked a bimodal response in the vSub-NAc pathway: a transient decrease in vSub-NAc drive followed by a sustained (i.e., $>40 \mathrm{~min}$ ) potentiation of this pathway. Floresco et al. (2001) have shown that the same tetanic stimulation used in the present study induced an increase in the vSub-dependent spiking activity of NAc neurons that is dependent on the activation of $D_{1}$ receptors, because injection of a $D_{1}$ antagonist induced LTD instead of LTP. However, the transient decrease was not observed in the previous study, because recordings were only initiated 2 min after stimulation, whereas in the present study, which used continuous pretetanus and postteta- nus recordings, the transient inhibition had a duration of only 1 min. This transient decrease was circumvented by systemic and by local (intra-NAc) administration of the $\mathrm{D}_{2}$ antagonist sulpiride. Thus, tetanic stimulation of the vSub-NAc pathway leads to liberation of dopamine in the NAc that appears to activate both $\mathrm{D}_{2}$ (present study) and $\mathrm{D}_{1}$ (Floresco et al., 2001) receptors by the tonic and phasic release of dopamine, respectively. Tonic activation of $\mathrm{D}_{2}$ receptors on $\mathrm{mPFC}$ afferents (O'Donnell and Grace, 1998) has been shown to modulate synaptic plasticity in the NAc at mPFC inputs (i.e., inhibition of LTP) (Goto and Grace, 2005b). Moreover, in the present study, we have shown that inactivation of the mPFC inhibits the vSub-NAc pathway, which is similar to the transient inhibition observed just after hippocampal tetanization. Thus, this transient inhibition of vSub-NAc drive after tetanization would be expected to occur via a $\mathrm{D}_{2}$-mediated attenuation of the vSub-mPFC-NAc pathway. Therefore, tonic activation of $\mathrm{D}_{2}$ receptors on $\mathrm{mPFC}$ afferents (O'Donnell and Grace, 1998) by DA release into the NAc after hippocampal tetanization can block mPFC effects in the NAc. As shown with inhibition of mPFC afferents by TTX, inhibition of this component by $\mathrm{D}_{2}$ receptor activation supports the requirement of mPFC in mediating vSub-dependent spiking activity of NAc neurons.

\section{The modulatory influence of the mPFC on the vSub-NAc pathway is $D_{2}$ dependent}

Interestingly, although the $\mathrm{mPFC}$ was not required to support vSub-NAc drive after vSub tetanus, we found that the injection of sulpiride before tetanus restored the requirement of the $\mathrm{mPFC}$ in the ability of the vSub to drive NAc neuron firing. Indeed, when sulpiride is injected before the tetanus and infusion of TTX, inhibition of the MPFC with TTX induced a depotentiation of the vSub-NAc pathway. However, if sulpiride is injected after tetanus, TTX in the mPFC has no effect on the LTP previously induced. The mechanism by which this reversal of LTP is produced is unclear. Nonetheless, the data suggest that sustained induction of mPFC-independent LTP in the vSub-NAc pathway appears to depend on $\mathrm{D}_{2}$ receptor stimulation during tetanic stimulation, because in the absence of this stimulation the vSub-NAc potentiation retains a requirement for $\mathrm{mPFC}$ contribution. It should be noted that $\mathrm{D}_{2}$ receptors blockade had no effect on the induction and maintenance of the LTP.

Anatomical (French and Totterdell, 2002, 2003) and electrophysiological (O'Donnell and Grace, 1995) studies have shown that the vast majority, if not all, medium spiny neurons in the NAc receives prominent convergent glutamatergic inputs from the vSub and the mPFC that overlap with dopaminergic inputs from the VTA (Mogenson and Yang, 1991). Although it is likely that the interaction between the MPFC and vSub occurs via convergent synaptic input onto single medium spiny neurons, it is known that the rat NAc also contains intrinsic, local circuit connections and interneurons (Hussain et al., 1996). Therefore, participation of multisynaptic pathways in the responses observed cannot be excluded.

\section{Functional implications}

The results reported here have important implications for normal learning processes as well as in pathological states. Thus, it is well known that the vSub plays a role in context-dependent processes (Jarrard, 1995; Maren and Quirk, 2004) that regulate learning via afferents to the NAc (Goto and Grace, 2005a). The current study demonstrates that the MPFC plays an essential facilitatory role in regulating vSub-NAc information flow, which may be 
A

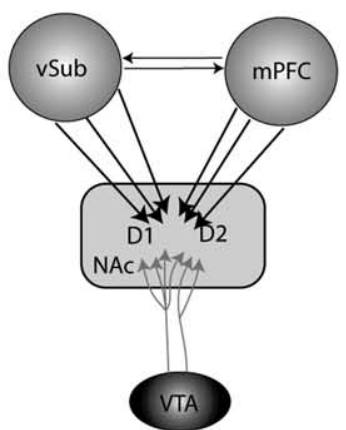

B

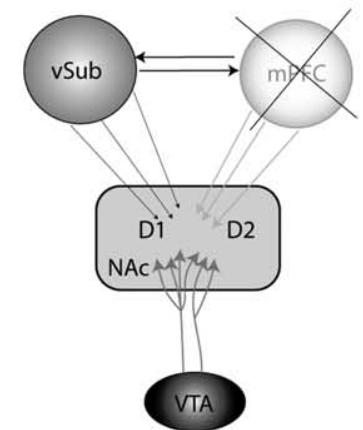

C

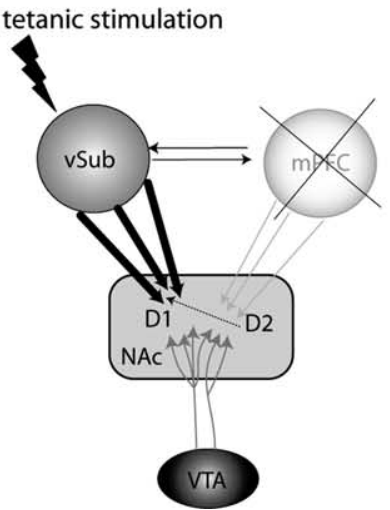

D

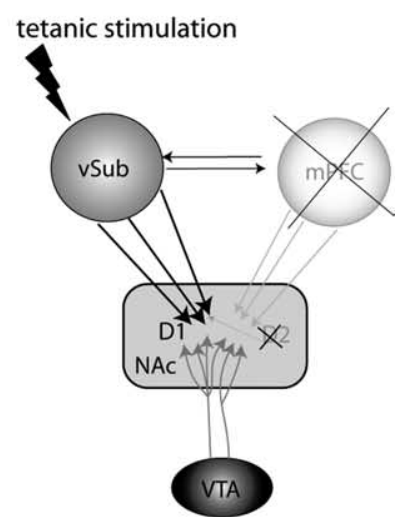

Figure 7. Schematic illustrating the vSub and the mPFC interactions to the NAc. $A$, The NAc receives concomitant information from the mPFC and the vSub that are under dynamic regulation of the DA system from the VTA; DA facilitates vSub afferent input via $D_{1}$ receptors and attenuates $m P F C$ input via $D_{2}$ receptors. $B$, Inhibition of the mPFC by TTX attenuates the ability of the vSub to drive spike firing in the NAc. In addition to a direct drive from the vSub, a contribution of the vSub-mPFC-NAc indirect pathway is necessary for the activation of the NAc by the vSub. C, If tetanic stimulation is first applied to the vSub, inactivation of the MPFC fails to affect the vSub-NAc pathway, suggesting that once the vSub-NAc pathway is enhanced via LTP, the mPFC is no longer required to drive spike firing. LTP in the vSub is apparently under the influence of $D_{2}$ receptors expressed in the accumbens (dashed arrow). $\boldsymbol{D}$, When the $D_{2}$ receptor antagonist sulpiride is injected before the tetanic stimulation is applied to the vSub-NAc pathway, inactivation of mPFC reverses the vSub-NAc LTP. This suggests that $D_{2}$ blockade restored the requirement of an intact vSub-mPFC-NAc pathway to enable direct activation of NAc by the vSub.

essential in the initial formulation of behavioral responses. However, once the vSub-NAc pathway undergoes LTP, such as may occur with a well learned contextual relationship, the mPFC no longer appears to be required. Under this condition, the system would be positioned to enable a more rapid response in known situations without the necessary intervention of higher cognitive structures.

In contrast, several studies have implicated increased hippocampal activity in the pathophysiology of schizophrenia (Heckers, 2001; Medoff et al., 2001). Moreover, hippocampal hyperactivity is directly associated with psychosis in schizophrenia (Liddle et al., 1992; Silbersweig et al., 1995; Molina et al., 2003), which is believed to be a DA-dependent process (Lodge and Grace, 2007). We have shown in a developmental animal model of schizophrenia that hyperactivity within the vSub drives a hyperdopaminergic state via the vSub-NAc projection (Lodge and Grace, 2007). It should be noted that the increase in nonpatterned activity that occurs in the vSub in animal models of schizophrenia is very different from what would be required to induce LTP (Lodge and Grace, 2007).

Although the current studies were performed in anesthetized, normal rats, the dependence of vSub-NAc drive on the mPFC may have direct relevance for patients with schizophrenia. Furthermore, there is substantial evidence that the amygdala may also play a role in schizophrenia (Reynolds, 1983). Indeed, we found that the amygdala can potently drive the vSub (Lipski and Grace, 2008) as well as influence the vSub-NAc pathway (Gill and Grace, 2008) and therefore likely participates in the gating effect observed.

Prefrontal leukotomy had been shown to be effective at relieving severe psychotic states in humans (Moniz, 1994), and lesions of the mPFC restored behavioral function as well as electrophysiological responses toward normality in an animal model of schizophrenia (Lipska et al., 1998; Goto and O'Donnell, 2004). Initially, these results were interpreted as a therapeutic effect resulting from disconnection of a dysfunctional PFC. However, in light of the current study, an alternate interpretation is that disconnection of the mPFC would circumvent the abnormal hyperactive vSub-NAc drive that we propose underlies the hyperdopaminergic state of schizophrenia.

\section{References}

Blaha CD, Yang CR, Floresco SB, Barr AM, Phillips AG (1997) Stimulation of the ventral subiculum of the hippocampus evokes glutamate receptormediated changes in dopamine efflux in the rat nucleus accumbens. Eur J Neurosci 9:902-911.

Bogerts B, Lieberman JA, Ashtari M, Bilder RM, Degreef G, Lerner G, Johns C, Masiar S (1993) Hippocampus-amygdala volumes and psychopathology in chronic schizophrenia. Biol Psychiatry 33:236-246.

Braff DL, Grillon C, Geyer MA (1992) Gating and habituation of the startle reflex in schizophrenic patients. Arch Gen Psychiatry 49:206-215.

Caine SB, Humby T, Robbins TW, Everitt BJ (2001) Behavioral effects of psychomotor stimulants in rats with dorsal or ventral subiculum lesions: locomotion, cocaine self-administration, and prepulse inhibition of startle. Behav Neurosci 115:880-894.

Falkai P, Bogerts B (1986) Cell loss in the hippocampus of schizophrenics. Eur Arch Psychiatry Neurol Sci 236:154-161.

Floresco SB, Yang CR, Phillips AG, Blaha CD (1998) Basolateral amygdala stimulation evokes glutamate receptor-dependent dopamine efflux in the nucleus accumbens of the anaesthetized rat. Eur J Neurosci 10:1241-1251.

Floresco SB, Blaha CD, Yang CR, Phillips AG (2001) Modulation of hippocampal and amygdalar-evoked activity of nucleus accumbens neurons by dopamine: cellular mechanisms of input selection. J Neurosci 21:2851-2860.

Floresco SB, West AR, Ash B, Moore H, Grace AA (2003) Afferent modulation of dopamine neuron firing differentially regulates tonic and phasic dopamine transmission. Nat Neurosci 6:968-973.

French SJ, Totterdell S (2002) Hippocampal and prefrontal cortical inputs monosynaptically converge with individual projection neurons of the nucleus accumbens. J Comp Neurol 446:151-165.

French SJ, Totterdell S (2003) Individual nucleus accumbens-projection neurons receive both basolateral amygdala and ventral subicular afferents in rats. Neuroscience 119:19-31.

Gill KM, Grace AA (2008) Regulation of information flow in the nucleus accumbens by hippocampus and amygdala. Soc Neurosci Abstr, in press.

Goldman-Rakic PS (1990) Cellular and circuit basis of working memory in prefrontal cortex of nonhuman primates. Prog Brain Res 85:325-335, discussion 335-336.

Goto Y, Grace AA (2005a) Dopaminergic modulation of limbic and cortical drive of nucleus accumbens in goal-directed behavior. Nat Neurosci 8:805-812.

Goto Y, Grace AA (2005b) Dopamine-dependent interactions between limbic and prefrontal cortical plasticity in the nucleus accumbens: disruption by cocaine sensitization. Neuron 47:255-266.

Goto Y, Grace AA (2006) Alterations in medial prefrontal cortical activity 
and plasticity in rats with disruption of cortical development. Biol Psychiatry 60:1259-1267.

Goto Y, O'Donnell P (2002) Timing-dependent limbic-motor synaptic integration in the nucleus accumbens. Proc Natl Acad Sci USA 99:13189-13193.

Goto Y, O’Donnell P (2004) Prefrontal lesion reverses abnormal mesoaccumbens response in an animal model of schizophrenia. Biol Psychiatry $55: 172-176$

Grace AA, Floresco SB, Goto Y, Lodge DJ (2007) Regulation of firing of dopaminergic neurons and control of goal-directed behaviors. Trends Neurosci 30:220-227.

Heckers S (2001) Neuroimaging studies of the hippocampus in schizophrenia. Hippocampus 11:520-528.

Hussain Z, Johnson LR, Totterdell S (1996) A light and electron microscopic study of NADPH-diaphorase-, calretinin- and parvalbumincontaining neurons in the rat nucleus accumbens. J Chem Neuroanat 10:19-39.

Jarrard LE (1995) What does the hippocampus really do? Behav Brain Res 71:1-10.

Laviolette SR, Grace AA (2006) Cannabinoids potentiate emotional learning plasticity in neurons of the medial prefrontal cortex through basolateral amygdala inputs. J Neurosci 26:6458-6468.

Liddle PF, Friston KJ, Frith CD, Hirsch SR, Jones T, Frackowiak RS (1992) Patterns of cerebral blood flow in schizophrenia. Br J Psychiatry 160:179-186.

Lipska BK, al-Amin HA, Weinberger DR (1998) Excitotoxic lesions of the rat medial prefrontal cortex. Effects on abnormal behaviors associated with neonatal hippocampal damage. Neuropsychopharmacology 19:451-464.

Lipski WJ, Grace AA (2008) Neurons in the ventral subiculum are activated by noxious stimuli and are modulated by noradrenergic afferents. Soc Neurosci Abstr, in press.

Lodge DJ, Grace AA (2007) Aberrant hippocampal activity underlies the dopamine dysregulation in an animal model of schizophrenia. J Neurosci 27:11424-11430.

Maren S, Quirk GJ (2004) Neuronal signalling of fear memory. Nat Rev Neurosci 5:844-852.

Medoff DR, Holcomb HH, Lahti AC, Tamminga CA (2001) Probing the human hippocampus using rCBF: contrasts in schizophrenia. Hippocampus 11:543-550.

Mogenson GJ, Yang CR (1991) The contribution of basal forebrain to limbic-motor integration and the mediation of motivation to action. Adv Exp Med Biol 295:267-290.
Molina V, Reig S, Pascau J, Sanz J, Sarramea F, Gispert JD, Luque R, Benito C, Palomo T, Desco M (2003) Anatomical and functional cerebral variables associated with basal symptoms but not risperidone response in minimally treated schizophrenia. Psychiatry Res 124:163-175.

Moniz E (1994) Prefrontal leucotomy in the treatment of mental disorders. 1937. Am J Psychiatry 151:236-239.

Mulder AB, Hodenpijl MG, Lopes da Silva FH (1998) Electrophysiology of the hippocampal and amygdaloid projections to the nucleus accumbens of the rat: convergence, segregation, and interaction of inputs. J Neurosci 18:5095-5102.

O’Donnell P, Grace AA (1994) Tonic D2-mediated attenuation of cortical excitation in nucleus accumbens neurons recorded in vitro. Brain Res 634:105-112.

O’Donnell P, Grace AA (1995) Synaptic interactions among excitatory afferents to nucleus accumbens neurons: hippocampal gating of prefrontal cortical input. J Neurosci 15:3622-3639.

O'Donnell P, Grace AA (1998) Dysfunctions in multiple interrelated systems as the neurobiological bases of schizophrenic symptom clusters. Schizophr Bull 24:267-283.

Paxinos G, Watson C (1996) The rat brain in stereotaxic coordinates. San Diego: Academic.

Raine A, Sheard C, Reynolds GP, Lencz T (1992) Pre-frontal structural and functional deficits associated with individual differences in schizotypal personality. Schizophr Res 7:237-247.

Reynolds GP (1983) Increased concentrations and lateral asymmetry of amygdala dopamine in schizophrenia. Nature 305:527-529.

Roberts AC, Robbins TW, Everitt BJ (1998) The prefrontal cortex; executive and cognitive functions. New York: Oxford UP.

Sherman AD, Davidson AT, Baruah S, Hegwood TS, Waziri R (1991) Evidence of glutamatergic deficiency in schizophrenia. Neurosci Lett 121:77-80.

Silbersweig DA, Stern E, Frith C, Cahill C, Holmes A, Grootoonk S, Seaward J, McKenna P, Chua SE, Schnorr L, Jones T, Frackowiak RS (1995) A functional neuroanatomy of hallucinations in schizophrenia. Nature 378:176-179.

Tamminga CA, Thaker GK, Buchanan R, Kirkpatrick B, Alphs LD, Chase TN, Carpenter WT (1992) Limbic system abnormalities identified in schizophrenia using positron emission tomography with fluorodeoxyglucose and neocortical alterations with deficit syndrome. Arch Gen Psychiatry 49:522-530.

Weinberger DR, Gallhofer B (1997) Cognitive function in schizophrenia. Int Clin Psychopharmacol 12 [Suppl 4]:S29-S36. 